\title{
Introduction
}

\author{
Shaker A. Zahra, Donald O. Neubaum and \\ James C. Hayton
}

This Handbook is the culmination of several years of research on corporate entrepreneurship (CE). This research has extensively covered the nature and scope of $\mathrm{CE}$ activities, focusing on strategic renewal, innovation and venturing activities within established companies. Research results suggest that $\mathrm{CE}$ is important for redefining a firm's business, market arena, business models, capabilities and skills, as well as for the way it conducts and organizes its operations. As such, CE allows the firm to change its identity as it navigates a constantly changing competitive terrain. It also allows the firm to develop new skills while leveraging existing ones, making it possible to envision new market arenas where the firm can exploit its capabilities. Innovation and venturing provide the knowledge essential for developing these capabilities.

The Handbook combines conceptual and empirical contributions that cover a wide gamut of theories and perspectives that include opportunity discovery vs. creation, behavioral theory of the firm, learning, human capital, agency and dynamic capabilities, among others. The chapters cover a wide range of dependent variables such as: who is the corporate entrepreneur; how corporate entrepreneurs vary from their independent counterparts; how CE influences organizational performance; and the effect of incremental vs. radical strategic renewal undertaken within CE on financial performance. It also covers what an organization learns, as well as what types of innovation companies gain through corporate venturing capital investments. The diversity of authors, perspectives and foci of the chapters highlights the growing depth and breadth of the worldwide research on $\mathrm{CE}$ and the growing maturity of this research.

The bulk of recent research has focused on organizational issues - such as structure, strategy and culture - that shape CE activities. This focus is understandable, given the importance of these variables in determining the pace, process and fate of venturing and innovation efforts. Consistent with this theme, this Handbook devotes considerable attention to some of these issues, hoping to synthesize what we know and clarify what we need to know in this regard, giving direction to future research. $\mathrm{CE}$ is about remaking organizations; it affects organizational cultures and systems 


\section{Handbook of research on corporate entrepreneurship}

which, in turn, influence the magnitude, direction and content of $\mathrm{CE}$ activities. Further, the chapters cover the valuable contributions of human capital on CE and vice versa.

The Handbook consists of three complementary parts: CE and internal venturing (Chapters 1-3); CE and organizational capability (Chapters 4-6); and corporate venture capital and external venturing (Chapters 7-10). The following is an overview of the chapters.

\section{CORPORATE ENTREPRENEURSHIP AND INTERNAL VENTURING}

This section deals with issues related to the domain, antecedents and effects of CE. It also focuses on internal corporate venturing activitiestheir motivations, management and organizational consequences. In addition it provides alternative definitions of corporate entrepreneurship and venturing by connecting these concepts to the definition of the broader field of entrepreneurship.

\section{CORPORATE ENTREPRENEURSHIP AND ORGANIZATIONAL CAPABILITY}

This section of the Handbook discusses the role of CE as key factor in building and revamping organizational capabilities and the conditions that govern this role. Authors relate $\mathrm{CE}$ to the notion of dynamic capabilities, sometimes viewing $\mathrm{CE}$ itself as a dynamic capability. Organizational challenges associated with links between $\mathrm{CE}$ and capabilities are a major topic of interest in the three chapters that tackle this complex subject. The literature highlights the importance of external environmental change in inducing and promoting CE.

\section{CORPORATE VENTURE CAPITAL AND EXTERNAL VENTURING}

One of the most important trends in CE research is the recognition of the growing role of corporate venture capital (CVC) as a source of funding entrepreneurial activities. CVC refers to partial equity investments made by incumbents in young startups. Typically, these are financial investments that also serve strategic functions such as organizational learning (see Chapters 7 and 9), gaining access to new technology and learning 
about technological discontinuities (Maula et al., 2013). They also give the firm access to a range of potential acquisition targets and alliance partners. Given the strategic benefits that both investing incumbent corporations and startups are likely to gain, CVC transactions are surrounded by uncertainty and complexity_potentially encouraging dysfunctional opportunism. This poses major challenges to value creation and capture in CVC. Four chapters address these issues.

\section{RESEARCH DIRECTIONS}

Every chapter in this Handbook identifies a number of interesting issues for future research. This is not surprising as there is a large body of literature on CE, spanning nearly five decades, as noted by Hill and Georgoulas. We know a great deal about the motivations for and antecedents of CE. We also know quite a bit about its strategic and financial implications. Still, we do not know as much about the mechanisms by which CE activities create and deliver value. The chapters in this Handbook point out that these mechanisms appear to vary by the approach the firm takes in conducting its $\mathrm{CE}$ activities. These mechanisms are likely to vary also between corporate venturing and internal venture development. For this reason, identifying and understanding relevant mechanisms will enhance future research and enrich managerial practice.

\section{Learning}

As several contributions in this Handbook would suggest (for example Chapters 8 and 9), learning is closely associated with CE. Most existing work on organizational learning within $\mathrm{CE}$ is conceptual and descriptive. There is a need for more empirical research on the nature, processes, mechanisms and consequences of this learning. Perhaps field studies and experiments might enable future researchers to provide more specific and focused insights into these fundamental issues. Specifically, when organizations learn from and through $\mathrm{CE}$ remain important research questions that require answers. What organizations learn is also important. Do firms learn different things from financial vs. strategic CVC activities, as the literature and several chapters in this Handbook suggest? If so, why; and what are the consequences of these differences in terms of learning and, as a result, firm performance? How do CVC investments influence capability building and exploitation in incumbents vs. new ventures?

Examining organizational learning highlights the need to think of $\mathrm{CE}$ as a source of unique knowledge that renews companies and allows them 


\section{$4 \quad$ Handbook of research on corporate entrepreneurship}

to chart new strategic initiatives (Zahra, 2015). This knowledge is multifaceted, which, when effectively deployed, could be strategically valuable. This suggests several questions for future inquiry:

- How does organizational learning yield firm-specific knowledge?

- How different is this knowledge from other types of knowledge an organization has?

- How do companies capture and harvest this knowledge?

- What processes and systems do companies use to transform and convert this knowledge into specific and unique applications and products?

- What are the organizational byproducts of the knowledge created within CE?

It is important also to differentiate between entrepreneurial and functional types of knowledge created within CE. Entrepreneurial knowledge relates to how companies stimulate and manage entrepreneurial activities, whereas functional knowledge relates more to how firms manage, organize, finance and structure their new ventures. By considering both types of knowledge, it becomes possible to identify, capture and exploit them in inducing and fueling future CE. For instance, it becomes easier for managers to train employees to identify relevant opportunities and evaluate their market potential. Similarly, it becomes easier to figure out how much autonomy a new venture should enjoy as it explores promising market opportunities and determines which organizational capabilities are useful in pursuit of new entrepreneurial initiatives.

\section{Time}

The temporal dimensions within CE antecedents and outcomes should also be examined. When does the external environment induce CE, and vice versa? Do companies that undertake CE change their industries in fundamental ways, and thus create a challenging competitive terrain for themselves and others? Another question that is not well understood in the literature is how long does it take for firms to benefit financially from CE investments and activities? Does this time horizon vary by the nature of the activity and/or the managerial practices associated with implementation? What is the effect of the external environment on this payoff time horizon? Longitudinal empirical research on CE is lacking, making it difficult to examine temporal relationships and causal mechanisms in effect. A major difficulty researchers may encounter is the informal nature of some $\mathrm{CE}$ activities. Yet, there are considerable amounts of archival 
data on different corporate venturing, opening the door for fruitful use of econometric studies with panel data. Such analyses will help resolve some of the persistent issues related to measuring corporate venturing activities and conceptualizing their causal chains.

\section{Temporary Advantage}

The fact that competitive advantage, in many industries, is temporary at best reinforces the need for commitment to and support of CE. It also requires a fresh look into the implications of continuous change for different competitive environments:

- Do corporations follow a portfolio approach when planning their $\mathrm{CE}$ activities to ensure enduring advantages?

- How do they sequence these activities to sustain advantage?

- How do they build relatedness among these activities?

- How do they leverage their skills across their different CE efforts?

- How do firms sustain flexibility in their resources, especially human capital?

- How do they shift resource use across different and oftentimes temporary CE efforts?

- What are the best ways companies use to integrate these resources?

- How is this integration achieved and sustained across the different organizational levels?

Constant shifts and changes of resources (for example, employee transfers) can create organizational fatigue, waste time, lead to lack of concentration and distract managerial attention - all of which can hurt performance and raise resistance to $\mathrm{CE}$. They may also lead employees to disengage from and not contribute to various $\mathrm{CE}$ activities.

\section{Internationalization}

One of the shortcomings of this Handbook is the absence of chapters that deal directly with the internationalization of CE. Venturing occurs on a worldwide scale. Mergers, acquisitions, joint ventures and alliances occur across international borders with high frequency. CVC is also international in its sources and targets. Funds received from CVCs support international expansion activities. Incumbents also actively collaborate with born global ventures or startups operating in foreign markets. Members of corporate spinoffs' top management teams also have significant levels of international experience, come from different countries and often have 


\section{Handbook of research on corporate entrepreneurship}

received their education in foreign countries. Despite these trends, there is little empirical research that tracks these forces and their effects on a firm's CE portfolio.

Lacking also are studies that show the effects of spillovers from a firm's international venturing on its operations elsewhere. For instance, it would be informative to examine how managers apply the learning that occurs in foreign markets to promote a firm's $\mathrm{CE}$ and innovation activities. Alternatively, it would be beneficial to explore how the CVC investments incumbents make in foreign startups affect their internationalization drive. The same goes for equity holdings in corporate spinoffs and how they may encourage incumbents to explore international markets or foreign sources of new technology. Zahra (2015) notes a virtuous cycle between CE and internationalization that generates significant, new knowledge. It would be important, therefore, to study this cycle and its implications for knowledge creation, a key source of innovative business models as well as value creation in international markets.

The preceding observations suggest several additional directions for future research. The internationalization of competition and industries often pressure companies to innovate in their different activities, such as CE. It would be helpful to examine the direct effect of these competitive changes on the use of internal vs. external modes of corporate venturing. Attention should be given also to linking the nature of competition and the use of different external venturing models, such as alliances, spinoffs, de novo venture creation, $\mathrm{CVC}$ and joint ventures. The international business literature has studied some of these issues as part of examining the mode of foreign market entry. The entrepreneurial and strategic motivations for the use of particular modes require greater attention and documentation. Researchers need also to connect the dominant strategic thrust of the incumbents' global vs. international vs. regional strategies on the portfolio of their foreign venturing.

\section{CREATING STRATEGIC VARIETY THROUGH CE}

The various chapters in this Handbook speak to the variety of CE activities. Some are internal and others are external; both could be informal or formal - even though there is greater recognition in the literature of informal or autonomous internal CE. External venturing takes many formssuch as CVC, spinoff, new venture creation and so on. These various $\mathrm{CE}$ forms play different roles in filling gaps in incumbents' resources, knowledge and capabilities. These modes also have different track records of influencing a firm's financial performance. Overall, companies seem to 
develop and maintain a portfolio of these activities, as rightly noted by Keil et al. in Chapter 9). But we know little about the sources of variety in a firm's CE portfolio. Perhaps the external environment is a major source of this variation. Institutional forces and imitative behaviors may also play a key role in this regard. The firm's resources and capabilities are another source. Power distribution among members of incumbents' top management teams, as well as agency issues, may be at the root of this variability. These and other explanations need to be considered and evaluated in future research to improve our understanding of how CE activity portfolios develop, how they might change, and under what conditions.

\section{CE and Organizational Capabilities}

Conceiving, undertaking and institutionalizing $\mathrm{CE}$ activities require recognition of and attention to networks, both formal and informal. Formal networks are crucial for successful external venturing where connections to other companies matter. One key motivation for external venturing is gaining access to capabilities and resources, particularly knowledge. Interorganizational networks are important in this regard. Surprisingly, little empirical work has investigated the effect of these networks directly on venturing activities as part of the broader CE concept. There is, of course, a vast body of research on the role of inter-organizational networks for facilitating innovation as well as acquisitions, yet how these networks may induce $\mathrm{CE}$ remains a relatively under-studied territory.

There is also a need to consider intra-firm networks and their effect on CE. The literature highlights the role of organizational champions in the success of formal and informal CE activities. In particular, it underscores champions' role in gaining corporate acceptance for CE efforts as well as institutionalizing them within the formal structure. Future research would benefit from systematically examining the networks of these champions and their sources of power within CE. What role does the social capital of these champions play? How does this role change over the course of $\mathrm{CE}$ initiatives' life cycles? Conversely, how does participation in CE influence champions' (and other employees') social capital? It is possible that CE success can enhance capital, whereas failure may damage it. Similarly, people are drawn from different functions within the organization to develop their own networks that can influence the flow of knowledge, resources and communication; these intra-organizational networks can determine the fate of CE initiatives.

As the above observation would suggest, greater attention to the "relational perspective" is essential in future CE research to understand the role of networks. Social capital is an important and scarce currency in 


\section{Handbook of research on corporate entrepreneurship}

any organization. It would be worthwhile, therefore, to examine its role in determining the development and fate of CE activities. This should provide important clues as to how different networks are formed or transformed, and how social capital is gained and lost within CE processes.

The role of dynamic capabilities in ensuring successful organizational adaptation and performance is well recognized in the literature, though the texture and nature of these capabilities remain a source of disagreement. Researchers (for example, Hughes et al., Basu et al. and Keil et al.) agree that $\mathrm{CE}$ can be a valuable source of capabilities that allow firms to adopt and seize opportunities in their markets, whether existing or new. In particular, a key objective of many $\mathrm{CE}$ activities is gaining access to the knowledge essential to revamping, upgrading or replacing existing capabilities or creating new to the world capabilities (Basu et al.). Consequently, how $\mathrm{CE}$ activities translate into specific capabilities is an important research question that deserves exploration. In particular, we need to know how the knowledge gained from CE is converted into capabilities. It is easier to see the link between particular formal CE activities and capability building - as happens in the case of technology acquisitions intended to increase a firm's innovative capacity. Yet, the link between informal $\mathrm{CE}$ and capabilities is harder to see and document, though few would doubt its existence and importance.

Another issue that requires research attention is the role of CE in transforming ordinary or functional capabilities into dynamic ones. What role does the new knowledge created within CE play in this regard? As noted by Keil et al., this knowledge should be integrated and synchronized to create combinations or bundles of knowledge that serve as components of capabilities. This, too, raises additional questions: How is this integration achieved? Are there specific actions that employees and managers follow to ensure this integration? An important byproduct of this integration is the diffusion of learning that occurs while developing capabilities. Part of this learning serves as a key mechanism for diffusing knowledge about the nature and role of these capabilities (Zahra, 2015). Wider acceptance and diffusion of capabilities, in turn, can give the firm a new set of strategic weapons that enable it to compete differently and create (or protect) its competitive advantage.

\section{Opportunity Perspective and CE}

Definitions of entrepreneurship abound, but one of the most popular regards entrepreneurship as the nexus of the relationship between the individual and opportunity. Research on CE has long focused on the creation of new businesses within established companies, and the strategic renewal of their ongoing operations. As such, there is no contradiction between 
definitions of independent entrepreneurship and CE. Yet, the application of the "opportunity perspective" in the study of CE has been slow. As a result, we do not know how individuals working within companies go about finding opportunities. Though companies often define opportunities on a scale and scope that differ significantly from individuals, we need to understand how corporate entrepreneurs discover and create opportunities. Under what conditions do they engage in discovery and when do they create opportunities? Zahra (2008) suggests a virtuous cycle where discovery can lead to creation and vice versa. This raises the question: When does this cycle persist? When does it turn into a vicious cycle, where discovery stifles creation and vice versa? Other interesting questions arise when we consider the "opportunity perspective" within CE. For example, how do individual entrepreneurs differ from their corporate counterparts in evaluating opportunities? Typically, multiple groups participate in evaluating opportunities within a firmapplying different financial, marketing and strategic criteria. These groups also have different preferences, motivations and styles. Therefore, we need empirical research that documents the effect of these various groups, operating at multiple levels, on how opportunities are evaluated.

\section{CONCLUSION}

As the chapters in this Handbook would attest, research on CE is growing in scope, methods and impact. This research has canvassed important and complex issues. Given the changes taking place in the global economy, the need for internal and external venturing continues to rise-demanding additional research that will create new theory and provide compelling evidence on the usefulness and impact of investments companies make in CE. This research will also show how and when CE becomes an instrument of innovation, strategic renewal and venturing that allows firms to compete and retain their advantages - or even create new sources of advantage in rapidly changing markets.

\section{REFERENCES}

Maula, M.V.J., T. Keil and S.A. Zahra (2013), 'Top management's attention to discontinuous technological change: corporate venture capital as an alert mechanism', Organization Science, 24, 926-47.

Zahra, S. (2008), 'The virtuous cycle of discovery and creation of entrepreneurial opportunities', Strategic Entrepreneurship Journal, 2, 243-57.

Zahra, S. (2015), 'Corporate entrepreneurship as knowledge creation and conversion: the role of entrepreneurial hubs', Small Business Economics, 44, 727-35. 
Shaker A. Zahra, Donald 0. Neubaum, and James C. Hayton - 9781785368738 Downloaded from PubFactory at 04/26/2023 $03: 55: 19$ AM 